\title{
Оцінка втрати років життя, скоригованих за якістю (QALY), пов'язаних зі смертністю від COVID-19 в Україні
}

Мета - оцінити ймовірні втрати років життя, скоригованих за якістю (Quality-adjusted life-year - QALY), пов'язаних із передчасною смертю від COVID-19 в Україні, на основі адаптації міжнародної методології (Briggs A., 2020 a; b) i стандартних методів з використанням таблиць смертності та врахуванням вікової структури і потенційного впливу супутніх захворювань у локальних умовах. Об’єкт і методи дослідження. Нами адаптовані вхідні параметри моделі, базово представлені даними Великої Британії, до українських локальних умов на основі опублікованих таблиць смертності та вікової структури смертності від COVID-19 в Україні з використанням програми «Mісrosoft Ехсеl». Biкова структура смертності від COVID-19 представлена за даними Центру громадського здоров'я Міністерства охорони здоров'я України (станом на 08.05.2020 р.). Результати. За результатами дослідження встановлено, що смерть від COVID-19 пов'язана зі значною втратою QALY в Україні за трьома сценаріями - від 6 до 13 втрачених років якісного життя. Втрати внаслідок смертності від COVID-19 в Україні становлять 2295-4525 QALY на популяцію залежно від впливу супутніх захворювань. Висновки. Встановлено, що в Україні на одну собу втрачається на 55,2\% більше QАLY порівняно з Великою Британією, що зумовлено різною віковою структурою смертності від COVID-19. Отже, у країнах із невисокою захворюваністю показник втрати QALYє важливим параметром, який потребує врахування для удосконалення надання медичної допомоги та фармацевтичного забезпечення під час пандемії.

Ключові слова: QALY, очікувана тривалість життя, COVID-19, коронавірусна хвороба.

\section{Вступ}

Під час пандемії COVID-19 практично всі епідеміологічні моделі $є$ основою для рекомендацій у прийнятті управлінських рішень, спрямованих на зниження захворюваності, з метою уникнення перевантаження системи охорони здоров'я (Giordano G. et al., 2020; van Elsland S., O'Hare R., 2020; Verity R. et al., 2020). У відповідь на пандемію багатьом країнам довелося запровадити різкі законодавчі обмеження, щоб забезпечити фізичну ізоляцію, що має негативний вплив на економіку в усьому світі. Науковці оцінюють, які основні уроки можна вивчити, щоб зменшити величезні економічні та соціальні витрати цієї пандемії, і які можуть дати відповіді майбутнім кризам, наприклад важливість прозорості, солідарності, координації дій, рішучості, ясності, підзвітності тощо (Forman R. et al., 2020). Однак, переходячи від тривалого періоду ізоляції та карантину до зменшення обмежень, настав час подумати над тим, щоб вийти за рамки простої метрики «врятованих років життя». В інші, менш складні часи, втрачені роки життя (Years of life lost), втрачені роки життя внаслідок настання непрацездатності або передчасної смерті в результаті захворювання (Disability-adjusted life year) або втрачені роки життя, скориговані за якістю (Quality-adjusted life-year QALY), є більш звичними інструментами для інформування політики (Briggs A., 2020a; b).

Мета - оцінити ймовірні втрати QALY, пов'язані з передчасною смертю від COVID-19 в Україні, на основі адаптації міжнародної методології та стандартних методів з використанням таблиць смертності й урахуванням вікової структури та потенційного впливу супутніх захворювань.

\section{Об'єкт і методи дослідження}

Експертами з оцінки медичних технологій в Україні проведено адаптацію методології, розробленої науковцями міжнародної компанії «Avalon Health Economics LLC», яка фокусується на оцінці можливих втрат QALY, пов'язаних із COVID-19 (Briggs A., 2020a).

Наразі у світі опубліковано різні дані щодо тягаря смертей, пов'язаних із COVID-19, для систем охорони здоров'я. Наприклад, дані свідчать про те, що рівень смертності від COVID-19 є прямо пропорційним до віку пацієнтів, та що люди з наявними супутніми захворюваннями є особливо вразливими. Нами були адаптовані вхідні параметри моделі, базово представлені даними Великої Британії, до українських локальних умов на основі опублікованих таблиць смертності та вікової структури смертності від COVID-19 в Україні з використанням програми «Microsoft Excel».

У проведеному аналізі оцінено такі параметри:

- очікувана тривалість життя (life expectancy - LE);

- QALY.

Методика заснована на використанні стандартних таблиць смертності, отриманих з офіційних джерел статистики, а саме «Таблиці народжуваності, смертності та середньої очікуваної тривалості життя за 2018 рік» (Державна служба статистики України, 2019). Таблиці використані для отримання очікуваної тривалості життя за віком, яку можна коригувати за допомогою визначеного стандартизованого коефіцієнта смертності (standardized mortality rate - SMR), з метою врахування впливу супутніх захворювань на смертність. Передбачено три рівні впливу цих супутніх захворювань (коефіцієнта SMR), які визначають, наскільки ці захворювання підвищують ризик смерті (1 - відсутність впливу, 2 - середній вплив та 3 - сильний вплив).

Коригування за якістю життя досягається за допомогою опублікованих норм за результатами використання опитувальника EQ-5D для вимірювання показників якості життя всього населення, а також додатковим параметром для врахування очікуваного зниження рівня якості життя внаслідок наявності супутніх захворювань (quality of life change due to comorbidities). Оскільки наразі розрахованих норм показників якості життя на основі EQ-5D для України немає, для розрахунків взято дані з оригінального аналізу Великої Британії (Szende A. et al. (Eds.), 2014), що є обмеженням нашого дослідження. Вікова структура смертності від COVID-19 отримана за даними Центру громадського здоров'я Міністерства охорони здоров'я України станом на 08.05.2020р.

\section{Результати та їх обговорення}

Станом на 08.05.2020 р. в Україні зареєстровано 14195 випадків інфікування COVID-19 та 361 летальний випадок, 2706 пацієнтів одужали (Центр громадського здоров'я України, 2020). 74,5\% померлих від ускладнень COVID-19 мали серцево-судинні захворювання, цукровий діабет, новоутворення, захворювання нирок, печінки, легень, неврологічні хвороби та ожиріння. 
Таблиця. Результати моделювання втрат QALY залежно від вікової структури смертності від COVID-19 в Україні за трьома сценаріями впливу супутніх захворювань

\begin{tabular}{|c|c|c|c|c|c|c|c|}
\hline \multirow[t]{2}{*}{ Вік, років } & \multirow{2}{*}{$\begin{array}{c}\text { Смертність } \\
\text { за віком в Україні } \\
\text { (станом } \\
\text { на } 08.05 .2020 \text { р.) }\end{array}$} & \multicolumn{2}{|c|}{$\begin{array}{c}\text { Сценарій } 1 . \\
\text { Відсутні супутні захворювання }\end{array}$} & \multicolumn{2}{|c|}{$\begin{array}{c}\text { Сценарій } 2 . \\
\text { Супутні захворювання } \\
\text { середньої тяжкості }\end{array}$} & \multicolumn{2}{|c|}{$\begin{array}{c}\text { Сценарій } 3 . \\
\text { Тяжкі супутні } \\
\text { захворювання }\end{array}$} \\
\hline & & LE $_{1}$ & QALY & $\mathbf{L E}_{2}$ & QALY, & $\mathbf{L E}_{3}$ & QALY $_{3}$ \\
\hline $0-9$ & $0,00 \%$ & 67,30 & 59,54 & $59,2^{2} 6$ & $47,94^{2}$ & 54,55 & $39,59^{3}$ \\
\hline $10-19$ & $0,83 \%$ & 57,43 & 49,65 & 49,47 & 39,11 & 44,85 & 31,81 \\
\hline $20-29$ & $0,28 \%$ & 47,76 & 40,39 & 40,05 & 30,97 & 35,61 & 24,71 \\
\hline $30-39$ & $3,60 \%$ & 38,52 & 31,76 & 31,29 & 23,58 & 27,25 & 18,42 \\
\hline $40-49$ & $9,42 \%$ & 30,01 & 23,90 & 23,65 & 17,15 & 20,26 & 13,15 \\
\hline $60-69$ & $27,70 \%$ & 15,07 & 11,38 & 10,92 & 7,49 & 8,99 & 5,51 \\
\hline $70-79$ & $22,44 \%$ & 9,20 & 6,67 & 6,17 & 4,03 & 4,84 & 2,81 \\
\hline $80-90$ & $15,24 \%$ & 4,97 & 3,61 & 2,96 & 1,94 & 2,15 & 1,25 \\
\hline $90-100$ & $0,55 \%$ & 2,43 & 1,73 & 1,39 & 0,90 & 1,20 & 0,68 \\
\hline \multicolumn{2}{|c|}{ Середньозважений показник } & 16,24 & 12,54 & 12,09 & 8,51 & 10,09 & 6,36 \\
\hline
\end{tabular}

у таблиці наведено результати моделювання, отримані на основі адаптації методології, а також обчислено середній показник втрат із інформації про вікову структуру смертності від COVID-19.

За результатами дослідження встановлено, що навіть при коригуванні на підвищення природної смертності залежно від віку, наявних супутніх захворювань та зниження якості життя, смерть від COVID-19 пов'язана зі значною втратою QALYв Україні за трьома сценаріями. У середньому серед усіх вікових категорій для людини, яка помирає від COVID-19 і у якої:

- немає супутніх захворювань, QALY становлять 13 років;

- $є$ супутні захворювання середньої тяжкості, QALY становлять 9 років;

- $€$ супутні захворювання великої тяжкості, QALY становлять 6 років.

Отже, в Україні в середньому серед усіх вікових категорій людина з наявними тяжкими супутніми захворюваннями, яка помирає від COVID-19, усе одно втрачає 6 років якісного життя.

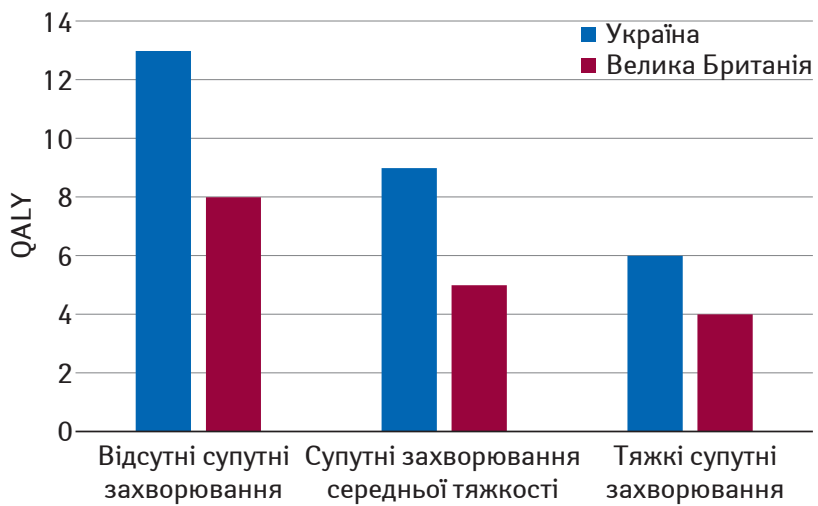

Рис. 1. QALY внаслідок смерті від COVID-19, відповідно до тяжкості супутніх захворювань, на одну особу в середньому серед усіх вікових категорій в Україні та Великій Британіі
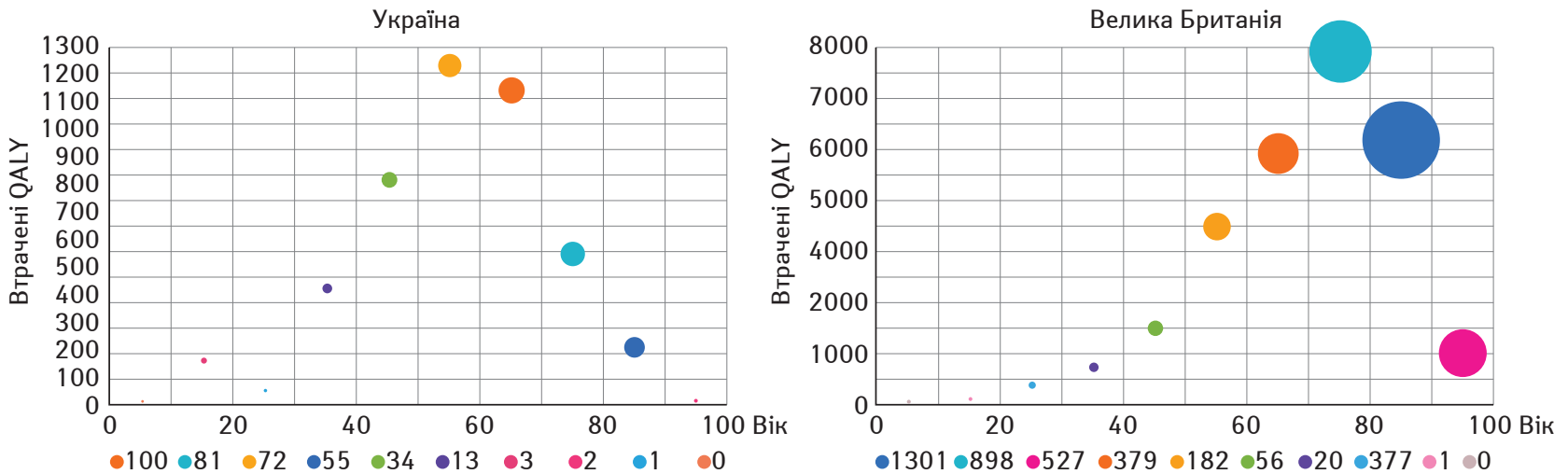

Рис. 2. Загальна втрата QALY внаслідок смерті від COVID-19 за віковою структурою смертності на когорту в Україні та Великій Британії без супутніх захворювань

Розмір бульбашки показує кількість смертей у відповідній віковій категорії. кої Британії та визначено, що в середньому серед усіх вікових категорій для людини, яка помирає від COVID-19, QALY становлять 8; 5 та 4 роки залежно від сценарію, що представлено на рис. 1. Оскільки у Великій Британії інша вікова структура смертності від COVID-19, яка припадає переважно на пацієнтів віком 80-90 років, порівняно з Україною (60-69 років) (рис. 2), результати аналізу свідчать, що в Україні на одну особу втрачається більше років за якістю на 55,2\% (у разі сценарію відсутності супутніх захворювань; за іншими сценаріями показник ще вищий).

Втрати внаслідок смертності від COVID-19 в Україні станом на 08.05.2020 р. становлять 4525 років якісного життя за відсутності у пацієнтів супутніх захворювань, 3071 років якісного життя за наявності супутніх захворювань середньої тяжкості та 2295 років якісного життя - за наявності тяжких супутніх захворювань.

Результати дослідження свідчать, що в Україні QALY внаслідок смертності від COVID-19 становить у середньому 6-13 років якісного життя серед пацієнтів усіх вікових категорій із тяжкими супутніми захворюваннями. Порівняльним аналізом встановлено, що в Україні на одну особу втрачається на $55,2 \%$ більше років життя, скоригованих за якістю, порівняно з Великою Британією, що зумовлено різною віковою структурою смертності від COVID-19 у досліджуваних країнах.

Отже, у країнах із невисокою захворюваністю та різними віковими структурами смертності показник QALY є важливим параметром, який потребує врахування для удосконалення надання медичної допомоги та фармацевтичного забезпечення під час пандемії.

\section{Список використаної літератури}

Державна служба статистики України (2019) Таблиці народжуваності, смертності та очікуваної тривалості життя за 2018 piк (http://ukrstat.gov.ua/druk/ publicat/kat_u/2019/zb/08/zb tabl_nar_2018.pdf).

Центр громадського здоров'я України (2020) Статево-вікова структура смертей, спричинених COVID-19, станом на 08.05.2020 (https://www. facebook.com/phc.org.ua/photos/a.353782784746456/1898201586971227/ ?type $\left.=3 \& \_\mathrm{tn} \_=-\mathrm{R}\right)$. 
Briggs A. (2020a) Estimating QALY losses associated with deaths in hospital (COVID-19) (https://avalonecon.com/wp-content/uploads/2020/04/COVID19-QALYS-v3.pdf).

Briggs A. (2020b) Moving beyond 'lives-saved' from COVID-19 (https://www. Ishtm.ac.uk/research/centres-projects-groups/chil\#covid-19).

Forman R., Atun R., McKee M., Mossialos E. (2020) 12 Lessons learned from the management of the coronavirus pandemic, Health Policy, 2020, ISSN 0168-8510, 4 p. DOI: 10.1016/j.healthpol.2020.05.008.

Giordano G., Blanchini F., Bruno R. et al. (2020) Modelling the COVID-19 epidemic and implementation of population-wide interventions in Italy. Nat. Med., Apr. 22. DOI: $10.1038 / s 41591-020-0883-7$.

Szende A., Janssen B., Cabases J. (Eds.) (2014) Self-reported population health: An international perspective based on EQ-5D. Springer, Dordrecht, $210 p$. DOI: 10.1007/978-94-007-7596-1.

Van Elsland S., O'Hare R. (2020) COVID-19: Imperial Researchers Model Likely Impact of Public Health Measures (https://www.imperial.ac.uk/news/196234/ covid-19-imperial-researchers-model-likely-impact/).

Verity R., Okell L.C., Dorigatti I. et al. (2020) Estimates of the severity of coronavirus disease 2019: a model-based analysis. Lancet Infectious Diseases published online. DOI: 10.1016/S1473-3099(20)30243-7.

\section{Оценка потери лет жизни, скорректированных по качеству (QALY), связанных со смертностью от COVID-19 в Украине}

\section{О.Б. Пиняжко, Т.М. Думенко, Л.И. Ковтун, В.В. Середюк, О.А. Топачевский}

Резюме. Цель - оценка вероятных потерь лет жизни с поправкой на качество (QALY), связанных с преждевременной смертью от COVID-19 в Украине, на основе адаптации международной методологии (Briggs A., 2020a; b) и стандартных методов с использованием таблиц смертности и учетом возрастной структуры, а также потенциального влияния сопутствующих заболеваний в локальных условиях. Объект и методы исследования. Адаптированы входные параметры модели, базово представленные данными Великобритании, к украинским локальным условиям на основе опубликованных таблиц смертности и возрастной структуры смертности от COVID-19 в Украине с использованием программы «Microsoft Excel». Возрастная структура смертности от COVID-19 представлена по данным Центра общественного здоровья Министерства здравоохранения Украины (по состоянию на 08.05.2020 г.). Результаты. Смерть от COVID-19в Украине связана со значительной потерей QALY по трем сценариям - от 6 до 13 лет потерянных лет качественной жизни. Потери вследствие смертности от COVID-19 в Украине составляют от 2295 до 4525 QALY на популяцию в зависимости от влияния сопутствующих заболеваний. Выводы. В Украине на одного человека теряется на 55,2\% больше QALY по сравнению с Великобританией, что обусловлено разной возрастной структурой смертности от COVID-19. Следовательно, в странах с невысокой заболеваемостью показатель потери QALY является важным параметром, который требует учета для совершенствования оказания медицинской помощи и фармацевтического обеспечения в период пандемии.

Ключевые слова: QALY, ожидаемая продолжительность жизни, COVID-19, коронавирусная болезнь.

\section{Estimation of quality-adjusted life years (QALY) losses associated with COVID-19 deaths in Ukraine}

\author{
O.B. Pinyazhko, T.M. Dumenko, L.I. Kovtun, \\ V.V. Seredyuk, O.A. Topachevsky
}

Summary. Objective. This study aims to assess the probable loss of quality-adjusted life years (QALY) associated with premature death from COVID-19 in Ukraine, based on the adaptation of the international methodology (Briggs A., 2020a; b) and standard methods using life tables and taking into account the age structure as well as the potential impact of comorbidities in the local environment. Object and methods of research. We adapted the input parameters of the model, basically presented with data from the United Kingdom, to ukrainian local conditions based on published life tables and age structure of mortality from COVID-19 in Ukraine using «Microsoft Excel». Age structure of mortality from COVID-19 is presented by the data of the Center of Public Health of the Ministry of Health of Ukraine (08.05.2020). Results. According to the results of the study, we found that death from COVID-19 is associated with a significant loss of QALY in Ukraine in three scenarios: from 6 to 13 years of qualityadjusted life years. Losses due to mortality from coronavirus in Ukraine range from 2295 to 4525 QALY, depending on the impact of comorbidities. Conclusions. It was found that in Ukraine there is $55.2 \%$ more QALY Iosses per person compared to the United Kingdom, due to the different age structure of mortality from COVID-19. Thus, in low-incidence countries, QALY loss is shown to be an important parameter to consider in order to improve healthcare and pharmaceutical provision during the pandemic.

Key words: QALY, life expectancy, COVID-19, coronavirus disease.

\section{Адреса для листування:}

Піняжко Ореста Богданівна

02000, Київ, вул. Смоленська, 10

Державний експертний центр М03 України,

департамент оцінки медичних технологій

E-mail: pinyazhko@dec.gov.ua

Одержано 25.05.2020 